\title{
SCATTERING OF ULTRASONIC RADIATION IN POLYCRYSTALLINE METALS
}

W. ROTH

TECHNICAL REPORT NO. 52

NOVEMBER 26, 1947

RESEARCH LABORATORY OF ELECTRONICS MASSACHUSETTS INSTITUTE OF TECHNOLOGY 
The research reported in this document was made possible through support extended the Massachusetts Institute of Technology, Research Laboratory of Electronics, jointly by the Army Signal Corps, the Navy Department (Office of Naval Research), and the Air Force (Air Materiel Command), under the Signal Corps Contract No. W-26-039 sc-32037. 
MASSACHUSETTS INSTITUTE OF TECHNOLOGY

Research Laboratory of Electronics

Technical Report No. $52 \quad$ November 26, 1947

SCATTERING OF ULTRASONIC RADIATION IN POLYCRYSTALLINE METALS*

by

W. Roth

Abstract

A method for measuring absorption and velocity of ultrasonic radiation in the frequency range from 5 to $100 \mathrm{Mc}$ by use of pulse techniques is described. Results of such measurements performed on polycrystalline magnesium and aluminum as a function of frequency and grain size show that the absorption coefficlent varles linearly with frequency and inversely with grain size. The scattering power of a metal and the fidelity with which an ultrasonic pulse is transmitted is shown to depend on the elastic constants of the single crystals. Criteria are established for evaluating the fidelity of pulse transmission in cubic and hexagonal metals, and figures of merit for many such polycrystaline metals are given.

* This report is part of a thesis with the same title submitted in partial fulfiliment of the requirements for the degree of Doctor of Philosophy at the Massachusetts Institute of Technology (1947). 


\section{Introduction}

Within the past decade, particularly during the war, much interest developed in the techniques for utilizing high-frequency ultrasonic radiation. Although applications to methods for underwater communications have received the major share of publicity, much progress has also been made in the realm of ultrasonic propagation in solids. Researchers have employed the latter to investigate the fundamental elastic properties of matter, while engineers have employed such methods to detect and investigate macroscopic flaws in metals.

Huntington 5 have reported the results of both continuous wave (CW) and pulsed methods for determining the elastic constants of solids. Firestone ${ }^{6}$, Glacomini and Bertin1, ${ }^{7}$ and Trost ${ }^{8}$ have been active in applying ultrasonics to the testing of metals. Other specialized applications using ultrasonic radiation in both liquids and solids were developed during the war at the M.I.T. Radiation Laboratory 9,10 and the U. S. Navy Underwater Sound Laboratories.

1. L. Bergmann, "Ultrasonics", Wiley, New York (1939).

2. R. Bär, "Supersonic Measurement of Elastic Constants of Isotropic Solids", Helv. Phys. Acta, 13, 61 (1940).

3. R. F. Ludloff, "Ultrasonics and Elasticity", J. Acous. Soc., I2, 193 (1940).

4. S. Bhagavantam and J. Bhimasenacher, "Elastic Constants of Crystals", J. Proc. Indian Acad. Sci. A, 20, 298 (1944).

5. H. B. Huntington, "Ultrasonic Measurements on Single Crystals", RLE Technical Report No. 10, March 1947. 6. F. A Firestone, "Supersonic Reflectoscope", J. Acous. Soc., I7,

7. A. Giacomini and A. Bertini, "Supersonic Method for Testing Homogeneity of Solids", Ricerca Scientifica, 10, 921 (1939).

8. A. Trost, "Detecting Flaws with U.H.F. Sound Waves", Sheet Metal Industr. 255, Feb. 1944.

9. M. Cefola et al, "Application of Pulse Techniques to the Measurement of Supersonic Waves in Liquids", M.I.T. Rad. Lab. Report 963, March 1946.

10. D. Arenberg, "Supersonic Solid Delay Lines", M.J.T. Rad. Lab. Report 932, April i946. 
Despite the wealth of information concerning ultrasonic propagation in solids already available, there still remains a considerable vold in our knowledge of the phenomena experienced in the megacycle region. This arlses from two basic causes: first, the previous work on solids was restricted mainly to lower frequencies where greater thicknesses can be penetrated; and second, the applications which did involve higher frequencies were primarily of immediate englneering need during the war, and thus could not be spared for more basic research.

Although the fact that some polycrystalline solids transmit ultrasonic pulses with less attenuation and distortion than others was recognized by those at M.I.T. Radiation Laboratory working on delay Iines, 1 no verifled explanations were presented. An effective change in the attenuating properties of steel as the grain size was varied was reported by Firestone, but only a qualitative picture was given. Since these examples typify the state of the art at the close of the war, it was felt that research of a more fundamental nature was needed to explain some of the phenomena previously observed as well as to investigate propagation in polycrystalline metals at higher frequencies.

Accordingly, apparatus for the generation and detection of ultrasonic pulses operating in the frequency band from 5 to 100 megacycles per second (Mc) was designed and constructed, and an investigation of propagation in polycrystalline metals was initiated. In particular, specimens of the desired metals were annealed so as to obtain a series with graduated grain sizes, and the velocity of propagation and absorption were measured for longltudinal waves as a function of grain size and ultrasonic frequency.

\section{Experimental Procedure}

The measuring technique used to study uItrasonic absorption and velocity includes the following basic steps:

(a) generation of an electrical pulse of the desired frequency and pulse length;

(b) conversion from electrical to ultrasonic energy;

(c) transmission of the ultrasonic pulses through the metal specimen under investigation;

(d) conversion from ultrasonic to electrical energy; and finally,

(e) Interpretation of the electrical pulses to provide accurate measurement of relative intensities and time intervals.

1. Arenberg, loc. cit.

2. Firestone, loc. cit. 

are performed and interrelated. The electrical pulses having carrier fre- quencles anywhere in the band from 5 to $100 \mathrm{Mc}$ with corresponding pulse widths varying from 15 microseconds ( $\mu$ secs) to $2 \mu s e c s$ are generated by the transmitter. The output from this unit is applied to an $\mathrm{X}$-cut quartz plezoelectric crystal transducer by means of a short transmission ine where it is transformed into ultrasonic energy comprising a pulse packet of longitudinal elastic waves.

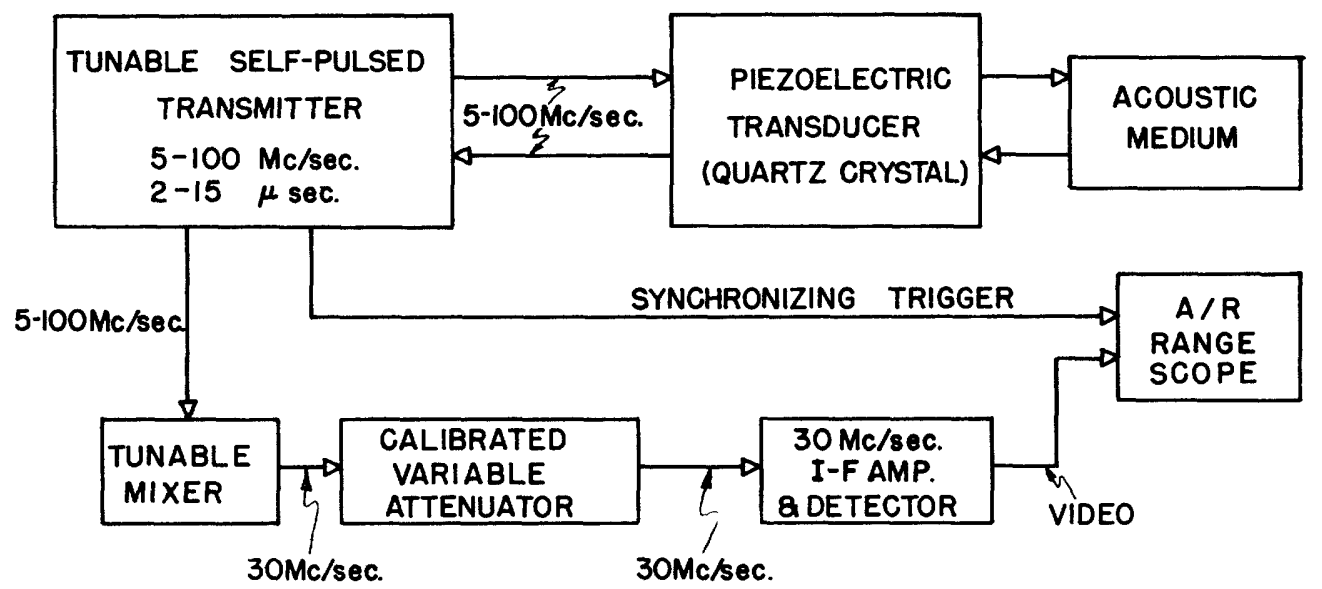

Figure 1. Block diagram of ultrasonic measuring equipment.

The crystal is acoustically loaded by a bath of distilled water in which is immersed the metal sample to be examined. The wave packet is transmitted through the water and into the metal specimen through which it propagates. After reflection from the second surface of the metal, the pulse returns through the water to the same transducer as that used for transmission. Here, it is reconverted to an electrical pulse, and is returned to the transmitter from which it is fed to the tunable mixer.

This latter element heterodynes the incoming pulse with a local oscillator (LO) signal and converts it to a pulse having a carrier frequency of $30 \mathrm{Mc}$ regardless of its original frequency. This converted pulse is fed to a calibrated variable attenuator which is used to measure its peak power. After further amplification and detection by a standard 30-Mc intermediate-frequency $(I-F)$ amplifier, the resulting video pulse is displayed on a cathode-ray oscilloscope. The scope used is a commercial instrument incluaing means for measuring time differences accurately. These are useful for determining the velocities of propagation of the ultrasonic pulses in the different metals. The synchronizing trigger, which is required to initiate the timing sweeps of the oscilloscope, is obtained - from the transmitter.

Figure 2 is a view of the experimental equipment as arranged for a run. (A) is the electrical console contalning the pulse generation and 


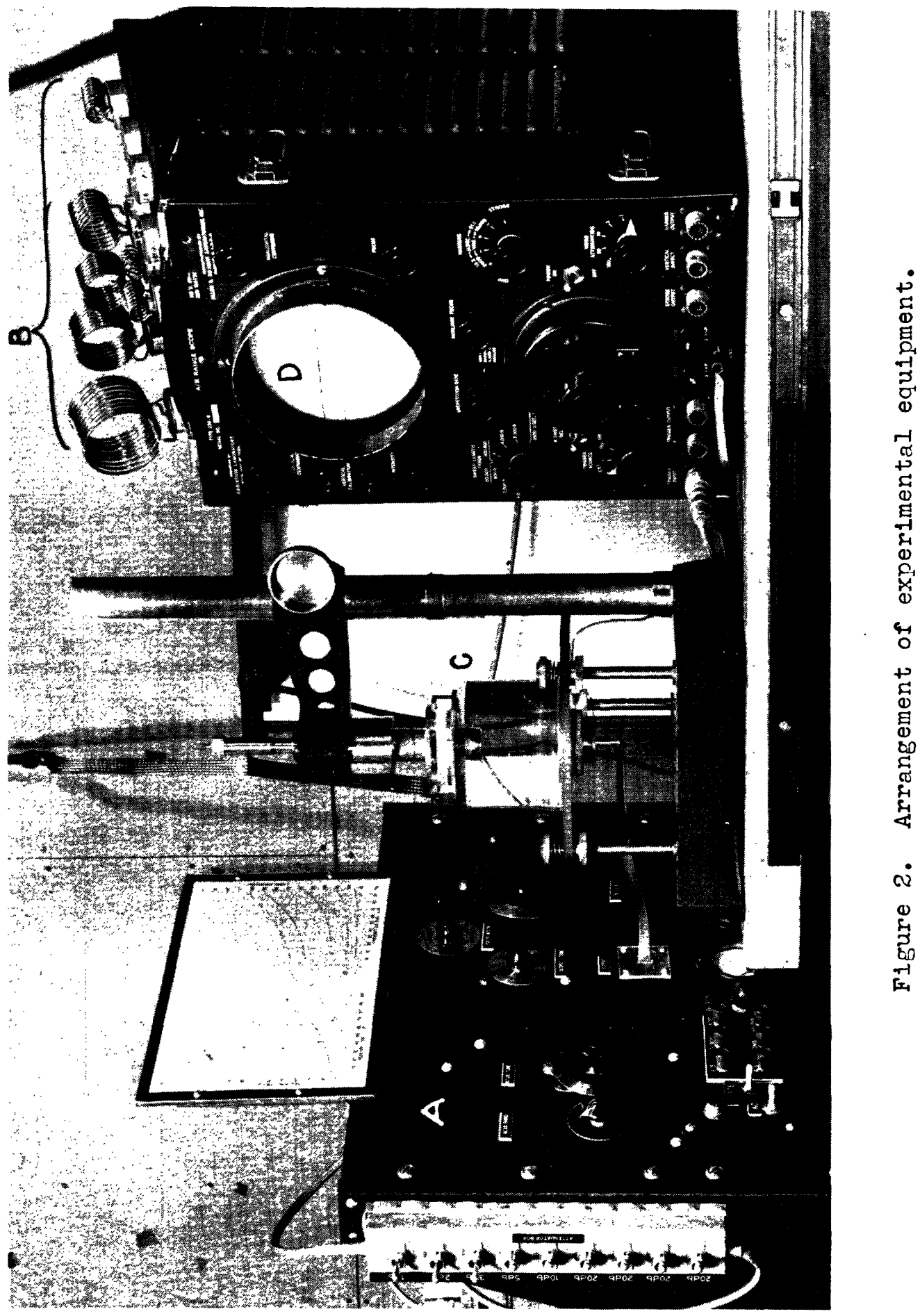


- reception circuits. The plug-in coils (B), are used for band switching to provide the wide frequency coverage desired: tuning within each band is done with the calibrated dials observed. on the panel. Peak electrical power output of 200 watts was measured at $25 \mathrm{Mc}$.

The electrical $r-f$ pulses are fed to the quartz crystal transducer mounted at the bottom of the glass test tank (C). Here, conversion to ultrasonic energy results in a beam about $1 / 4$ in. in diameter propagating upward in a distilled water bath. The metal under test is immersed in the Ilquid and intercepts the beam to produce patterns on the screen of the Dumont A/R Range Scope (D). Typical patterns are shown in Figs. 3 and 4. Figure $3 a$ shows echoes resulting from a homogeneous rod of fused quartz. Deflection is domward and time increases to the right. The first pulse at the left-hand edge of the sweep. is the main bang. The delay before the second pulse is due to the time of propagation in the liquid before the transmitted pulse strikes the first surface of the quartz. The reflection from the first surface produces the second echo which, in this case, is of sufficient intensity to overload the receiver.

The train of pulses following that caused by the first surface results from multiple reflections between the two parallel end surfaces of the quartz. The exponential decrease in amplitude should be noted; this occurs only when materials that appear homogeneous to the beam are used. Since fused quartz of the length used here, I $3 / 8$ in., has extremely low attenuation, the absorption indicated by this exponential envelope is princlpally due to the reflection loss at the water-quartz interface. The reflection coefficient at this boundary is not unity; hence, not all the energy continually reflects back and forth within the quartz; a fraction is lost each round trip and the exponential decay results.

Figure $3 b$ is a similar photograph showing the pattern obtalned for fine-grained magnesium. The only difference to be noted is the increased absorption in the solid as indicated by the increased slope of the exponential. Figure $3 \mathrm{c}$ is the result for coarse-grained magnesium. No exponential envelope is observed because the scattering and refraction processes resulting from the non-homogenelties of the large grains introduce interference effects. Thus, one pulse may be small due to phase cancellation, whlle the next may be large as a result of phase adaltion.

Figure $3 d$ is for aluminum and illustrates an effect previously absent; namely, energy return from metal grains located between the surfaces. This is indicated by the hump between the second and third pulses. A more extreme case of this phenomenon is shown in Fig. 4a. The metal here is brass, although this pattern is typical of most non-homogeneous anisotropic materials. In this case, the scattered energy from the grain boundaries is large enough to mask completely the energy reflected from the surfaces. No Measurements can be made with such a pattern. Figure $4 \mathrm{~b}$ is 
(a)

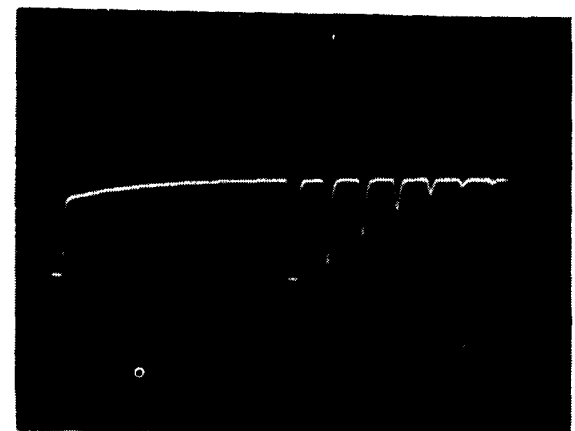

diam. $=\frac{1}{2}$ in. $f=28.2 \mathrm{Mc} / \mathrm{sec}$

length $=13 / 8 \mathrm{In}$. pulse width $=2.5 \mathrm{\mu sec}$ sweep length $=122 \mu \mathrm{sec}$

* $D=$ grain size.

(C)

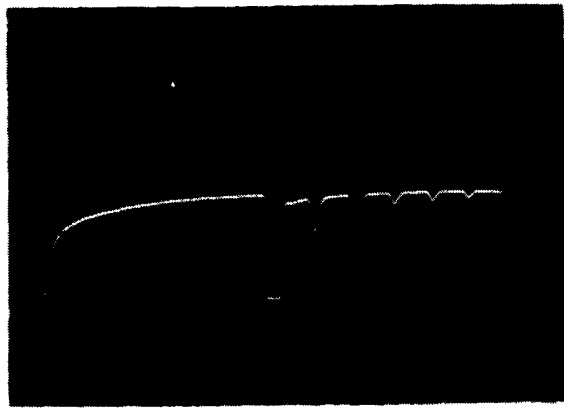

Magnesium

diam. = $1 \mathrm{in} . \quad f=16.9 \mathrm{Mc} / \mathrm{sec}$

length $=11 / 4 \mathrm{In}$. pulse width $=3.5 \mu \mathrm{sec}$

$\mathrm{D}=1.8 \mathrm{~mm}$

$D / \lambda=7.6$ (b)

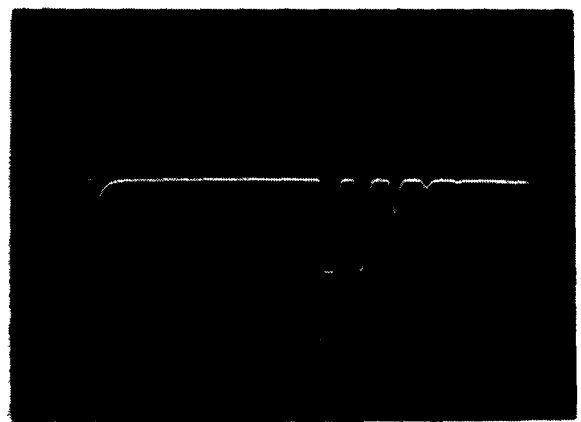

Magnesium

diam. $=I$ in. $\quad f=16.9 \mathrm{Mc} / \mathrm{sec}$

length $=1 l / 4$ in. pulse width $=3.5 \mu \mathrm{sec}$

$D=0.35 \mathrm{~mm}$

$D / \lambda=1.5$

(d)

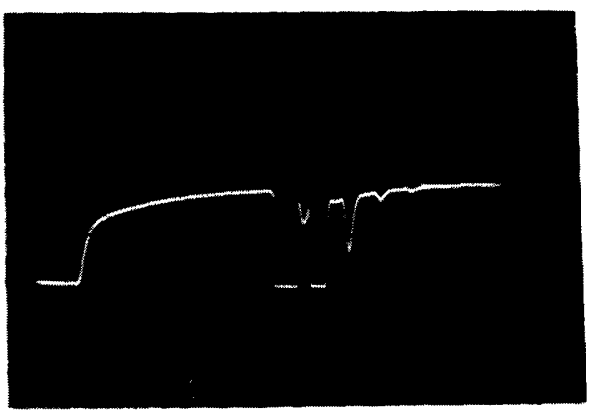

Alurninum

diam. $=3 / 4 \mathrm{in} . \quad f=16.9 \mathrm{Mc} / \mathrm{sec}$

length $=1 \frac{2}{2}$ 1n. puise width $=3.5 \mu \mathrm{sec}$

$D=0.21 \mathrm{~mm}$

$D / \lambda=0.88$

Figure 3.

exactly the same except that the pulse width is slightly greater. The general pattern is similar, but the detalled fluctuations are not. This implies that the increased length of the wave train has affected the phase relationships of the interference processes, producing altered patterns. Similar variations occur for the same reason if the frequency, or alignment of the sample with respect to the beam, is changed slightly.

Figure $4 \mathrm{c}$ is a view of a single pulse displayed on an expanded sweep in proper position for determinine 1 ts amplitude and the time elapsed with respect to the start of the sweep. No pulse distortion is evident since fine-grained magnesium was used. Figure $4 d$ is a similar view of aluminum showing considerable pulse distortion. No measurements can be made with such a pulse. 
(a)

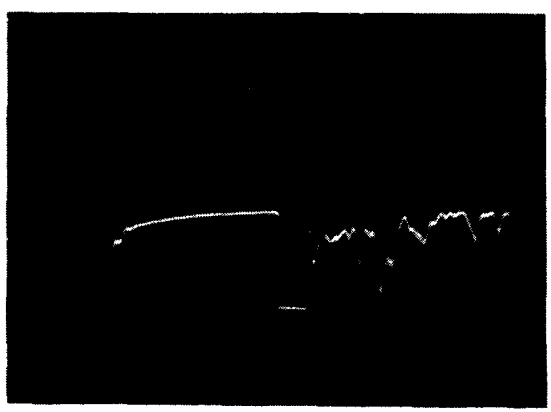

$$
\begin{array}{cl}
\text { Brass } & (70-30) \\
\text { 1-in. cube } & f=16.9 \mathrm{Mc} / \mathrm{sec} \\
& \text { pulse width }=3.5 \mu \mathrm{sec} \\
\text { sweep }=122 \mu \mathrm{sec}
\end{array}
$$

(c)

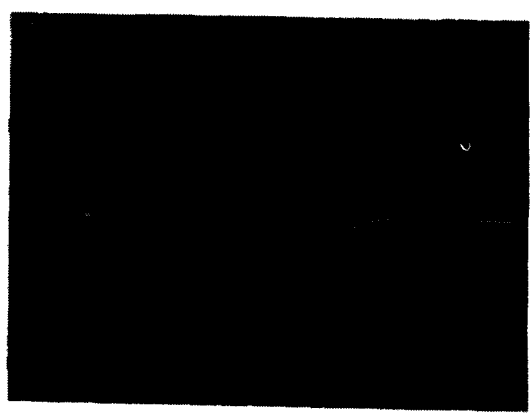

Magnesium

$$
\begin{aligned}
& \text { dlam. }=1 \text { in. } \quad f=28.2 \mathrm{Mc} / \mathrm{sec} \\
& \text { length }=1 \mathrm{l} / 4 \mathrm{in} \text {. pulse width }=2.5 \mu \mathrm{sec} \\
& D / \lambda \stackrel{\text { sweep }}{=2.5} \\
& \text { sweep }=12.2 \mu \mathrm{sec}
\end{aligned}
$$

(b)

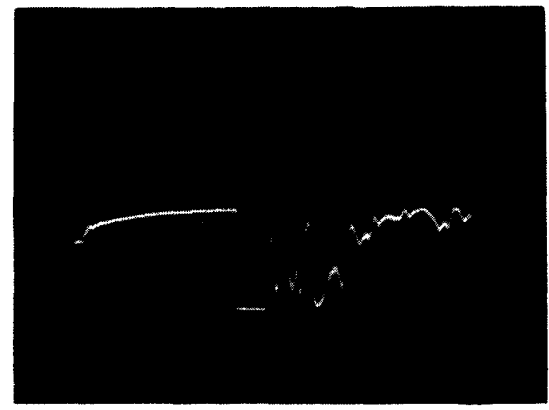

$$
\begin{array}{cl}
\text { Brass } & (70-30) \\
\text { 1-in. cube } & f=16.9 \mathrm{Mc} / \mathrm{sec} \\
& \text { pulse width }=3.7 \mu \mathrm{sec} \\
\text { sweep }=12.2 \mu \mathrm{sec}
\end{array}
$$

(d)

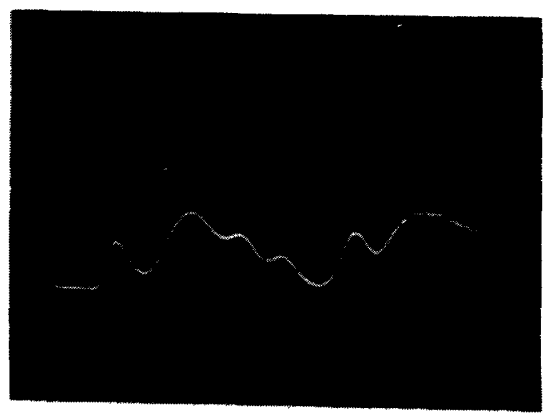

$$
\begin{array}{ll}
\text { diam. }=3 / 4 \mathrm{in} . & f=28.2 \mathrm{Mc} / \mathrm{sec} \\
\text { length }=1 \frac{1}{2} \mathrm{in} . & \text { pulse width }=2.5 \mu \mathrm{sec} \\
D=0.2 \mathrm{~mm} & \text { sweep }=24.4 \mu \mathrm{sec}
\end{array}
$$

* $D=$ grain size.

Figure 4.

\section{Experimental Results}

Six metals, magnesium, aluminum, copper, brass, nickel, and monel, were obtained in a cold-worked condition and were annealed in order to develop the desired grain sizes ${ }^{1}$. of the six, only magnesium and aluminum were suitable for measuring purposes since the pulse distortion when using the remalning four metals was prohibitive. The description of the magnesium and aluminum follows.

1. The heat treating and grain counting reported here was done by Mr. $D$. Essman under the supervision of Professor M. Cohen, both of the H.I.T. Department of Metaliurgy. 
TABLE I. Description of Metals Tested

\begin{tabular}{|c|c|c|}
\hline Nominal Composition & Forming Process & Supplier \\
\hline 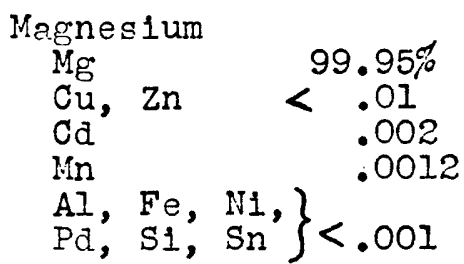 & $\begin{array}{l}\text { I" diam. round bar } \\
\text { extruded at } 410-450^{\circ} \mathrm{F} \\
\text { at a speed of } 1-2 \mathrm{ft} / \mathrm{min} \\
\text { with a reduction of } 9 \mathrm{x}\end{array}$ & Dow Chemical Co. \\
\hline $\begin{array}{l}\text { Aluninum } \\
\text { 2S commercially } \\
\text { pure, Al min. } \\
\text { 99\% }\end{array}$ & $\begin{array}{l}\text { cold-formed round bar } \\
3 / 4^{\prime \prime} \text { diam. with a } \\
\text { minimum of } 50 \% \text { cold } \\
\text { work }\end{array}$ & $\begin{array}{l}\text { Aluminum Company } \\
\text { of America }\end{array}$ \\
\hline
\end{tabular}

3.1. Attenuation. The results of measurements made on two representative mannesium specimens for different frequencies are plotted in Figs. 5 and 6 . The former, for a fine-gralned sample, appears to be homogeneous to the incident beam since the points on the logarithmic plots lie along straight

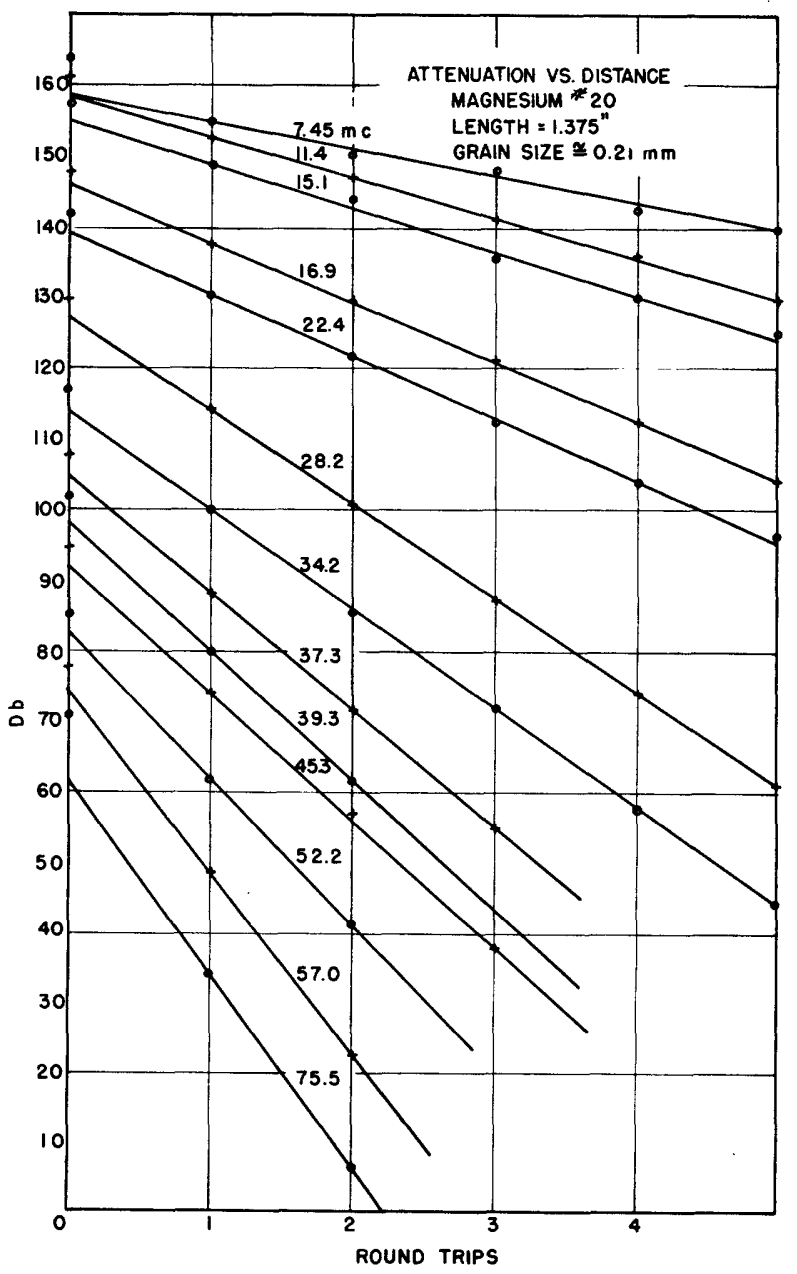

Figure 5. 


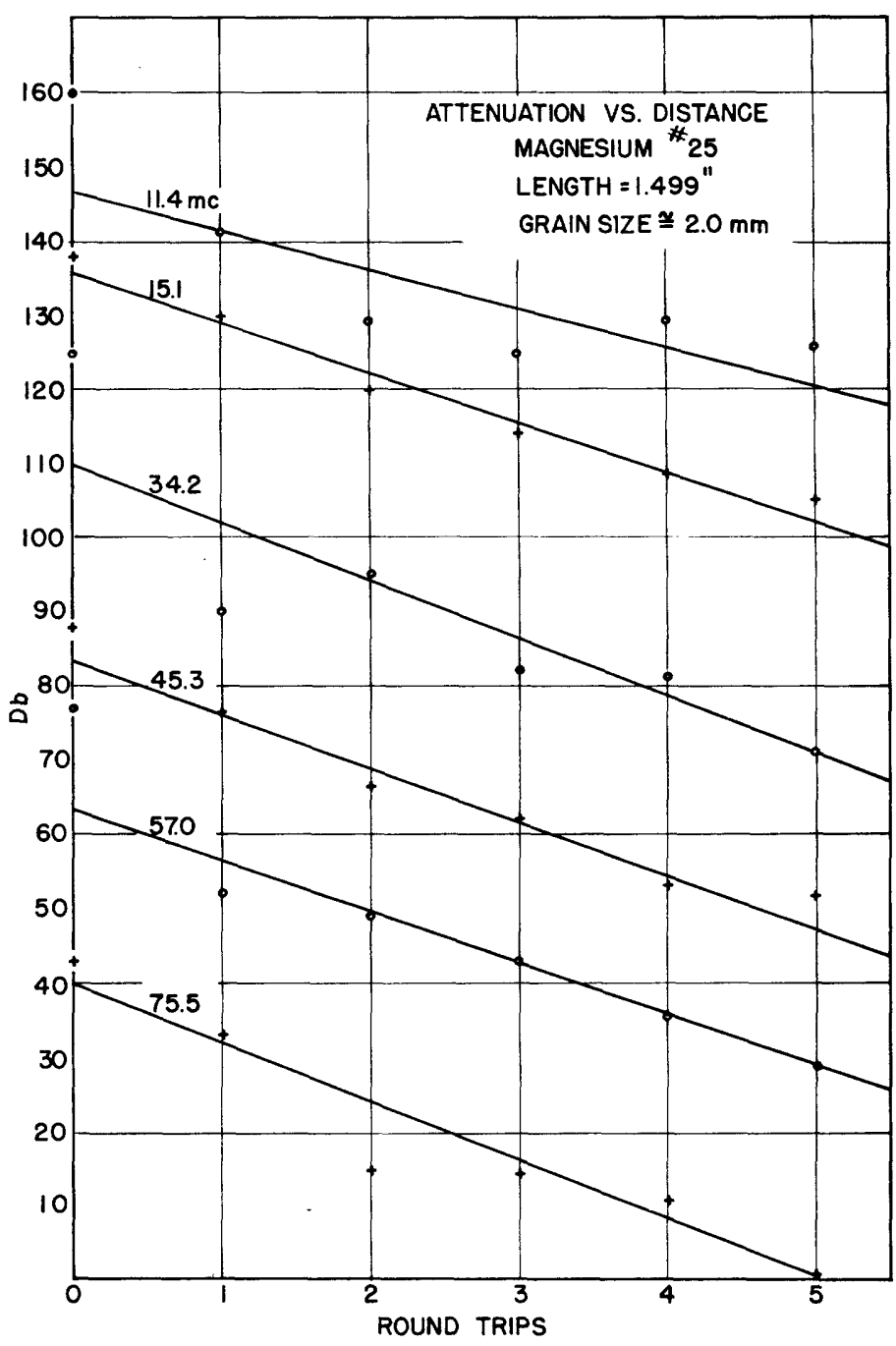

Figure 6.

Iines that correspond to time exponentials on the cathode-ray tube screen. The latter, for a coarse-grained sample, shows much departure from an exponential resulting from the large grains. The attenuation of the first sample can be measured accurately, whereas considerable error could be introduced in the second cese. These curves are typical of both good and bad experimental runs for magnesium and aluminum.

From the slopes of these curves and the power reflection loss at the water-metal interface, (see below), graphs of attenuation in the metal vs. frequency for different grain sizes can be plotted. Figure 7 illustrates such curves for the two samples referred to above. Although the large scatter of the individual points about the mean is disturbing, this is the nature of the processes under investigation, and cannot be avolded. The linear variation of attenuation with frequency should be noted. For grain sizes lying between the two cases shown, straight lines are also found, but the slopes assume values intermediate to those shown. 


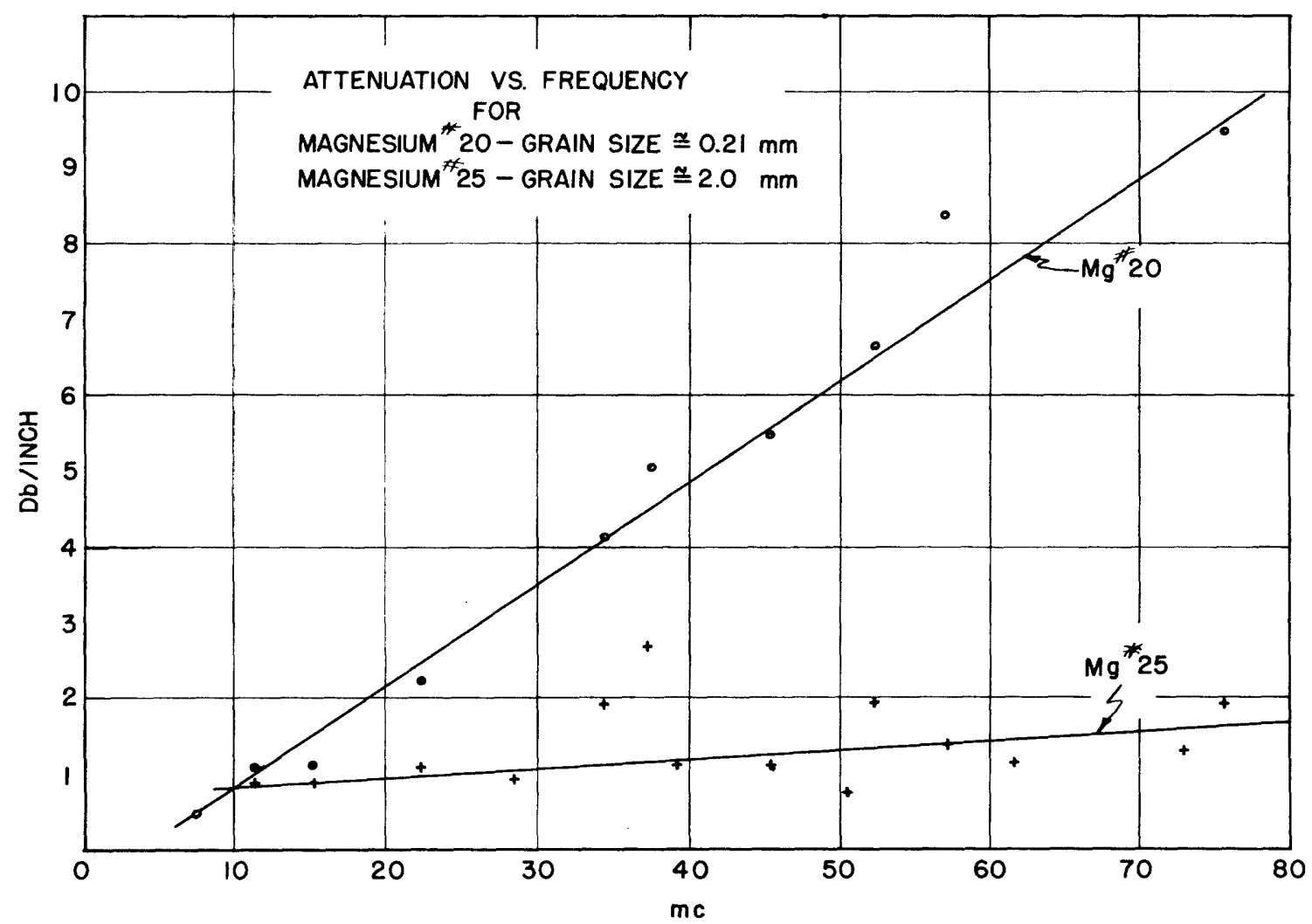

Figure 7.

Figure 8 is a plot of the slopes of the previous curves as functions of grain size. The attenuation $\alpha$ is stated in terms of the amplitude absorption coefficient rather than in decibels per inch, where $\alpha$ is defined from the relation

$$
I=I_{0} e^{-2 \alpha x}
$$

In which $I=$ intensity in a plane wave at point $x$

$$
\begin{aligned}
& I_{0}=\text { intensity in a plane wave at point } x=0 \\
& \alpha=\text { amplitude absorption coefficient. }
\end{aligned}
$$

The solid rectangles indicate the areas of error for the experimental results with magnesium, and the dotted rectangles indicate the same for aluminum. Although these areas are large, more information can be obtained from these data than is at first thought possible.

Even if a larger per cent error in grain size for the uppermost point were assumed, the actual grain size limits or width of this rectangle, would not be increased substantially. Simllarly, a larger per cent error in absorption per cycle for the point farthest to the right would not increase the helght of this rectangle greatly. Therefore, the extreme limits of the curve eventually drawn are rather well defined. If we now consider the number of curves that vill also pass through the center of 


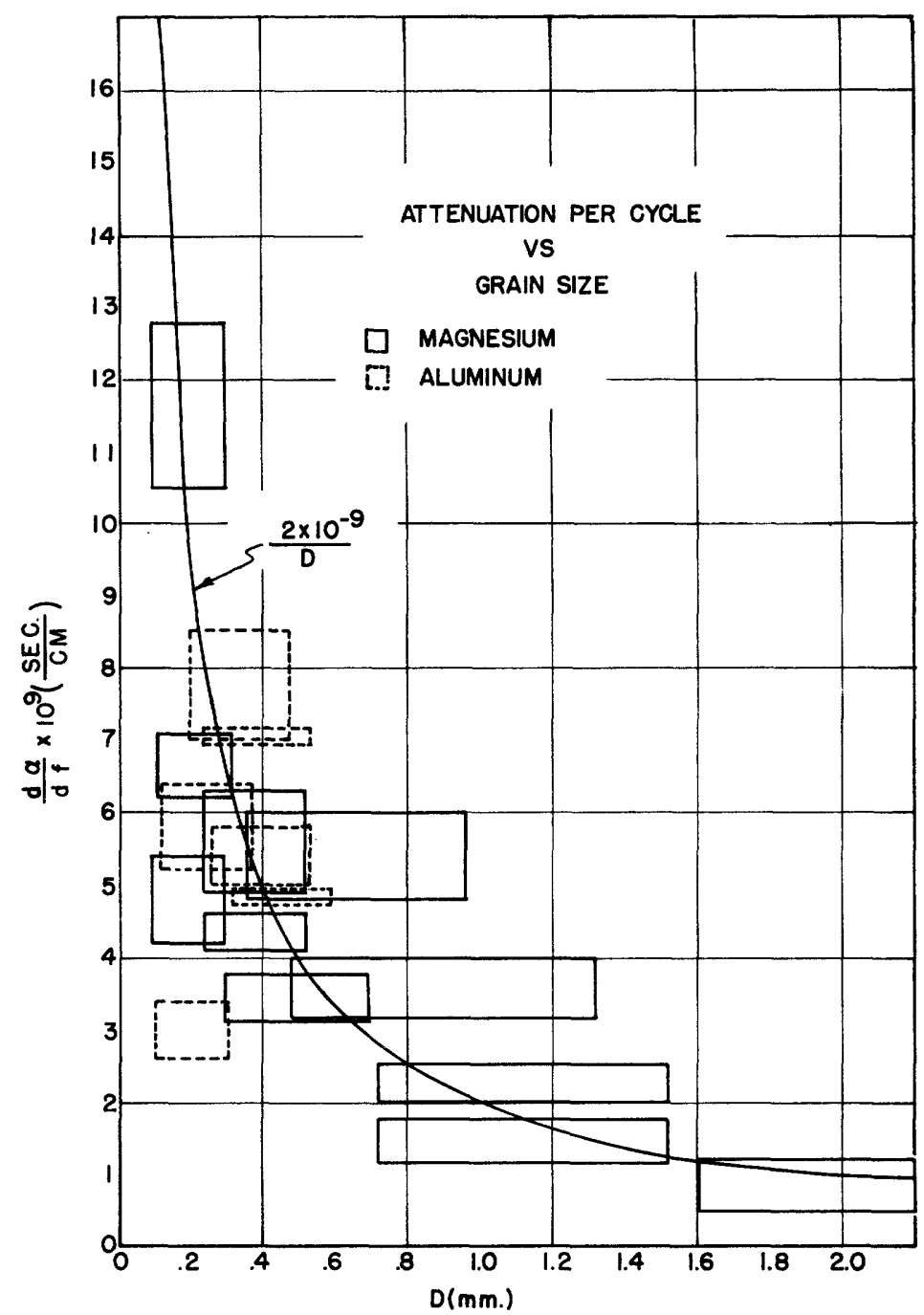

Figure 8.

distribution of the remaining rectangles, our choice is severely limited. The solid curve finally drawn is an equilateral hyperbola which gives

$$
\mathrm{d} \alpha / \mathrm{df}=2 \times 10^{-9} / \mathrm{D}
$$

or

$$
\alpha=2 \times 10^{-9} \frac{1}{D}+K(D) \mathrm{cm}^{-1}
$$

where

$$
f=\text { frequency in cycles/sec }
$$$$
D=\text { grain size in } \mathrm{mm}
$$

$$
K(D)=\text { a function independent of frequency but }
$$
possibly dependent on $D$, in $\mathrm{cm}^{-1}$. 
$K(D)$ is the value of $\alpha$ for elther $f=0$ or $D=\infty$, neither of which were obtained in these experiments. However, by extrapolating the attenuation vs. frequency curves to $f=0, K(D)$ is found to lie in the region bounded by $\pm .05 \mathrm{~cm}^{-1}$ for all the samples tested. It should be noted that this expression refers to the frequency band from 5-100 $\mathrm{Kc}$ and should not be considerec to apply outside tisis range without further experimental verification.

Power Reflection Coefficlent. The power reflection coefficient at the interface between two semi-infinite media is given in the usual way by

$$
R=\left(\frac{\rho_{1} V_{1}-\rho_{2} V_{2}}{\rho_{1} V_{1}+\rho_{2} V_{2}}\right)^{2}
$$

where $\rho=$ density, $V=$ velocity, and the subscripts refer to the respective media. Experimental determination of this quantity was performed by making two absorption-distance runs on each sample. The metal was completely immersed in water in one case, but only one surface was immersed in the other. Since the reflection at an air-to-metal boundary is essentially unity, the aifference in the attenuation in the two cases equals the reflection loss at one metal-water interface, or $-10 \log _{10} R$. Curves of these runs for the two magnesium specimens previously discussed are shown in Fig. 9. The vertical displacement between corresponding points of the two curves in each set equals $n \times 10 \log _{10} R$, where $n$ is the order of the round trip. From this measured reflection loss, $R$ was determined for each metal and checked against the value calculated from Eq. (3). The constants for water were taken from A. B. Wood, "Textbook of Sound". The results are:

\begin{tabular}{ccc} 
Metal & $\begin{array}{c}\mathrm{R} \\
\text { Observed }\end{array}$ & $\begin{array}{c}\mathrm{R} \\
\text { Calculated }\end{array}$ \\
\cline { 2 - 2 } & 0.558 & 0.561 \\
$\mathrm{Al}$ & 0.708 & 0.714
\end{tabular}

and the agreement is seen to be excellent.

It should be noted that this applies only for propagation from the metal to the rater and not in the opposite direction. When propagating into the metal, standing waves are set up at the surface layers because of the inhomogeneities, and the conditions for application of Eq. (3) are not present. This discrepancy was observed. The departure occurs at a lower frequency for larger greins, because the inhomogeneities assume importance at a lower frequency.

1. Bergmann, op. cit. 


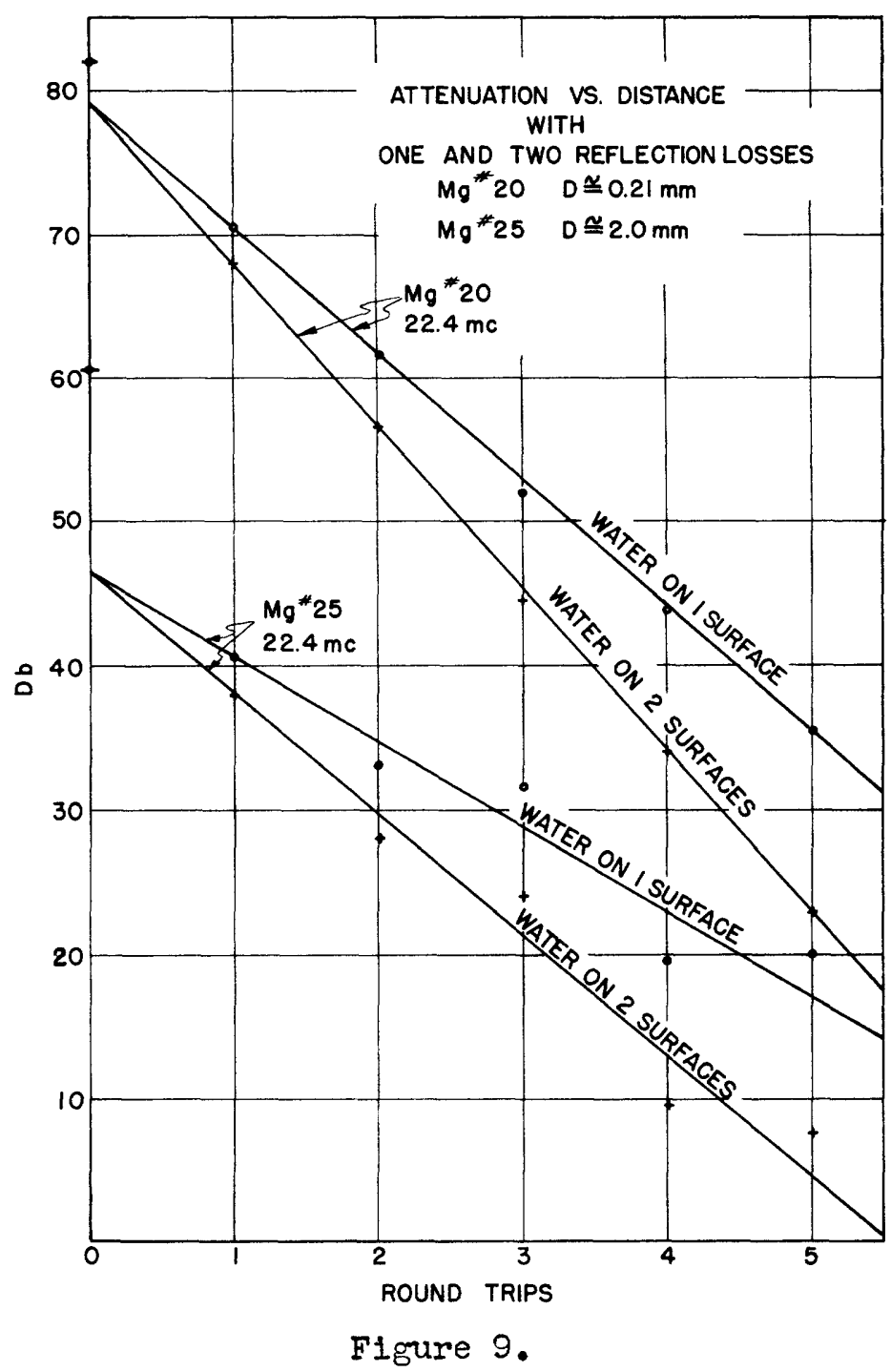

Velocity. The velocity of propagation of longitudinal waves in infinite plates is given by

$$
v^{2}=\frac{E(1-\sigma)}{\rho(1+\sigma)(1-2 \sigma)}
$$

where

$$
\begin{aligned}
& \rho=\text { density } \\
& \mathbf{E}=\text { Young's modulus, } \\
& \sigma=\text { Poisson's ratio. }
\end{aligned}
$$

This velocity is measured experimentally by dividing twice the sample length by the time difference between successive echoes. By using the known constants for the polycrystalline metal in question, Eq. (4) can be 
applied to check the experimental value. This was done for aluminum and is recorded in Table II.

For magnesium, no consistent constants for the polycrystaline metal could be found, so the results of calculations giving the velocity of propagation as a function of direction in a hexagonal crystal were used. The velocity for a polycrystalline sample represents a weighted average of all values present in the individual crystal. These are also tabulated below. The agreement in both cases is very good and no velocity dispersion was observed.

TABLE II.

\begin{tabular}{|c|c|c|c|}
\hline Metals & $\begin{array}{l}\text { Observed } \mathrm{V} \\
\text { in un1ts of } 10^{5} \mathrm{~cm} / \mathrm{sec}\end{array}$ & $\begin{array}{l}\text { Calculated } \\
\text { in units of } 10^{5} \mathrm{~cm} / \mathrm{sec}\end{array}$ & $\begin{array}{l}\text { Source of } \\
\text { elastic } \\
\text { constants }\end{array}$ \\
\hline $\mathrm{Mg}$ & $5.77 \pm .004$ & $\begin{array}{l}5.61-5.81 \\
\text { (for single crystal) }\end{array}$ & $\begin{array}{l}\text { R. F. S. Hearmon, } \\
\text { Rev. Mod. Phys. } \\
\frac{18}{1946, \text { (3) July, }} 409 .\end{array}$ \\
\hline AI & $6.31 \pm .01$ & 6.32 & $\begin{array}{l}\text { G. W. C. Kaye and } \\
\text { T. H. Laby "Table } \\
\text { of Phys. and } \\
\text { Chem. Constants", } \\
\text { Longman, Green, } \\
\text { I94I. }\end{array}$ \\
\hline
\end{tabular}

Comparison vith Published Resultg. Mason and McSkimmon ${ }^{1}$ recently published a paper reporting results of ultrasonic absorption measurements for aluminum made in the frequency range from 2 to $15 \mathrm{Mc}$. Since the conclusions based on their work are different from those reported here, a critical comparison is in order.

Although they report regults for both incident longltudinal and shear waves, only the former can be compared with those reported here, since no shear measurements have been made. Two serious disagreements and one agreement should be noted. First, they find attenuation varies with $D^{3}$ where we find a $1 / D$ relation; and, second, they report a variation with wavelength of $I / \lambda^{4}$ at low frecuencies, (changing in one case to $1 / \lambda^{2}$ at higher frequencies), while we find a $1 / \lambda$ variation. The agreement concerns the velocity measurements. They obtained $6.32 \times 10^{5}$ and the result stated here is $6.31 \pm .01 \times 10^{5} \mathrm{~cm} / \mathrm{sec}$.

1. W. P. Mason and H. J. McSkimmon, "Attenuation and Scattering in Metals and Glasses," J. Acous. Soc., I9, 468 (1947). 
- Unfortunately, the composition of the aluminum used in the two - cases was not the same, so the two sets of experimental absorption data cannot be plotted together to give results having much significance.

Aluminum 17ST, which they used, has a nominal composition of 95 per cent Al, 4 per cent $\mathrm{Cu}, 1 / 2$ per cent $\mathrm{Mn}$, and $1 / 2$ per cent $\mathrm{Mg}$, whereas the aluminum used here is better than 99 per cent pure. Although this difference in composition seems small, the attenuation found with the latter metal is about two times greater than the figure they report for the common frequency of $15 \mathrm{Mc}$ and common grain size of about $0.2 \mathrm{~mm}$. They do not state the mechanical or thermal treatment of the samples tested other than that "standard" rods having different grain sizes were used. It is here asgumed that they were commercial stock. without further annealing for strain relief or grain-size control.

Two different grain sizes were used in their experiments, and they state values for $D$ of $0.23 \pm .01 \mathrm{~mm}$ and $0.13 \pm .01 \mathrm{~mm}$, respectively. Since no special annealing procedures were employed to prepare these samples, it is difficult to see how grain size errors of only \pm 5 and \pm 10 per cent were obtained, when errors larger than \pm 50 per cent were found with the carefully prepared specimens used for the present work - - especially since lengths up to $12 \mathrm{in}$. were reportedly used, whereas only 1 $\frac{1}{2}-1$. samples were employed here. Commercial stock would not be strainfree with such uniform grain structure as that indicated. As a result, the conclusion that attenuation varies with $D^{3}$, formulated after testing only two different specimens with grain size values that are not accurately known, does not seem to be warranted.

The $1 / \lambda^{4}$ behavior they report is in distinct contrast to the $I / \lambda$ form found here. Although no estimate of experimental errors is included in their data, it appears as if straight lines can be plotted through their points as well as the fourth power curves found in the present work. If this is done, their curves become similar to the attenuation-versus-freauency curves found in the present research. The $D^{3} / \lambda^{4}$ varlation obtained by Mason and McSisimmon may, indeed, prove to be the case after more information is accumulated over wider frequency ranges, but from the nature of data on hand no justification for its adoption is apparent at the present time.

Explanation of Results. Since a polycrystalline metal is a tightly packed assembly of scattering elenents, the theories developed by Rayleigh ${ }^{l}$ and Morse ${ }^{2}$ for scattering of a plane wave by an isolated single scattering

\footnotetext{
1. Lord Rayle1gh, "Theory of Sound," Dover, New York (1945), pp. 420, 424, Vol. 2 .

2. P. M. Morse, "Vibration and Sound", McGraw-Hill, New York

- (1936), pp.265, 269.
} 
element should not be expected to apply. Hultiple or secondary scattering is neflected when extending the simple theory to loosely packed assemblies, but this cannot be done in the present case. The theoretical explanation of the experimentaliy determined expression for a given above must await more powerful techniques for handling multiple scattering from large assemblies of closely-coupled elements.

An explanation of the variation in the fldelity of pulse transmission through different polycrystalline metals is furnished by examining the velocity anisotropies for the single crystals of the metals in question. Using the method previously discussed by Christoffel ${ }^{1}$, Love ${ }^{2}$, and more recently by Mueller, 3 expressions for the velocities of propagation for the three possible modes in cubic and hexagonal crystals can be developed. For the surface planes of cubic crystals the equations are

$$
\begin{gathered}
k_{1,2}^{2}=\frac{\left(c_{11}+c_{44}\right) \pm \sqrt{\left(c_{11}-c_{44}\right)^{2}+\sin ^{2} 2 \varphi\left\{2 c_{44}\left(c_{11}+c_{12}\right)+c_{12}{ }^{2}-c_{11}{ }^{2}\right\}}}{\frac{1}{2}\left[4 c_{11} c_{44}+\sin ^{2} 2 \varphi\left\{c_{11}{ }^{2}-c_{12}{ }^{2}-2 c_{44}\left(c_{11}+c_{12}\right)\right\}\right]} \\
k_{3}^{2}=1 / c_{44}
\end{gathered}
$$

where $\frac{I}{k_{1} \sqrt{\rho}}$ is the velocity of propagation, $v_{1}$,

$$
\begin{aligned}
& \text { and } \rho=\text { density } \\
& c_{j k}=\text { elastic constants of the single crystal } \\
& \varphi=\begin{array}{l}
\text { angle of propagation in the surface planes } \\
\text { with respect to the } x, y, \text { or } z \text { axis. }
\end{array}
\end{aligned}
$$

For the xy planes of hexagonal crystals we have

$$
\mathrm{k}_{1}^{2}=\frac{2}{c_{11}-c_{12}}
$$

1. E. B. Christoffel, Ges. math. Abhandlungen, Bd2, 81, Leipzig (1910).

2. A. E. Love, "Mathematical Theory of Elasticity", Cambridge (1920) p. 303.

3. H. Mueller, "Intensity and Polarization of Light Diffracted by Supersonic Waves in Solids", Phys. Rev., 52, 223 (1937).

H. Mueller, "Determination of Elasto-Optical Constants with Supersonic Waves", Z. Kristallogr. (A) 99, 122 (1938). 


$$
\begin{aligned}
& k_{2}^{2}=\frac{1}{c_{11}} \\
& k_{3}^{2}=\frac{1}{c_{44}},
\end{aligned}
$$

which are independent of the angle of propagation. The velocities in hexagonal crystals in planes parallel to the $z$ axis are dependent upon angle and can be obtained from the equations:

$$
\begin{gathered}
k_{1,2}^{2}=\frac{b+\sqrt{b^{2}-4 a}}{2 a} \\
k_{3}^{2}=\frac{1}{\frac{1}{2}\left(c_{11}-c_{12}\right) \cos ^{2} \theta+c_{44} \sin ^{2} \theta}
\end{gathered}
$$

where

-

$$
\begin{aligned}
& a=\frac{1}{4} \sin ^{2} 2 \theta\left(c_{11} c_{33}-c_{13}{ }^{2}-2 c_{13} c_{44}\right)+c_{11} c_{44} \cos ^{4} \theta+c_{33^{4}} c_{44} \sin ^{4} \theta \\
& b=c_{11} \cos ^{2} \theta+c_{33^{8}} \ln ^{2} \theta+c_{44} \\
& \theta=\text { angle of propagation w1th respect to the } x y \text { plane. }
\end{aligned}
$$

Polar plots of the velocities in cubic aluminum and copper and hexagonal magnesium and zinc are given below in Figs. 10-13. The caption $L$ refers to the quasi-longitudinal mode polarized in the plane of propagation; $T_{I}$ refers to the quas1-transverse mode polarized normal to this plane, and $\mathbb{T}_{2}$ refers to the quasi-transverse mode polarized in the plane of propagation.

Aluminum, copper, and magnesium vere tested, and as noted above, copper was a poor transmitter, while aluminum and magnesium were good. Reference to the polar plots shows that copper is very anisotropic, while the other two are only slightly so. Although zinc was not tested, it has been included as an example of a highly anisotropic hexagonal metal which,

- therefore, should provide poor ultrasonic pulse transmission.

- A polycrystalline solia comprising an aहEregate of randomly

- oriented anisotropic grains scatters because discontinuities are presented 

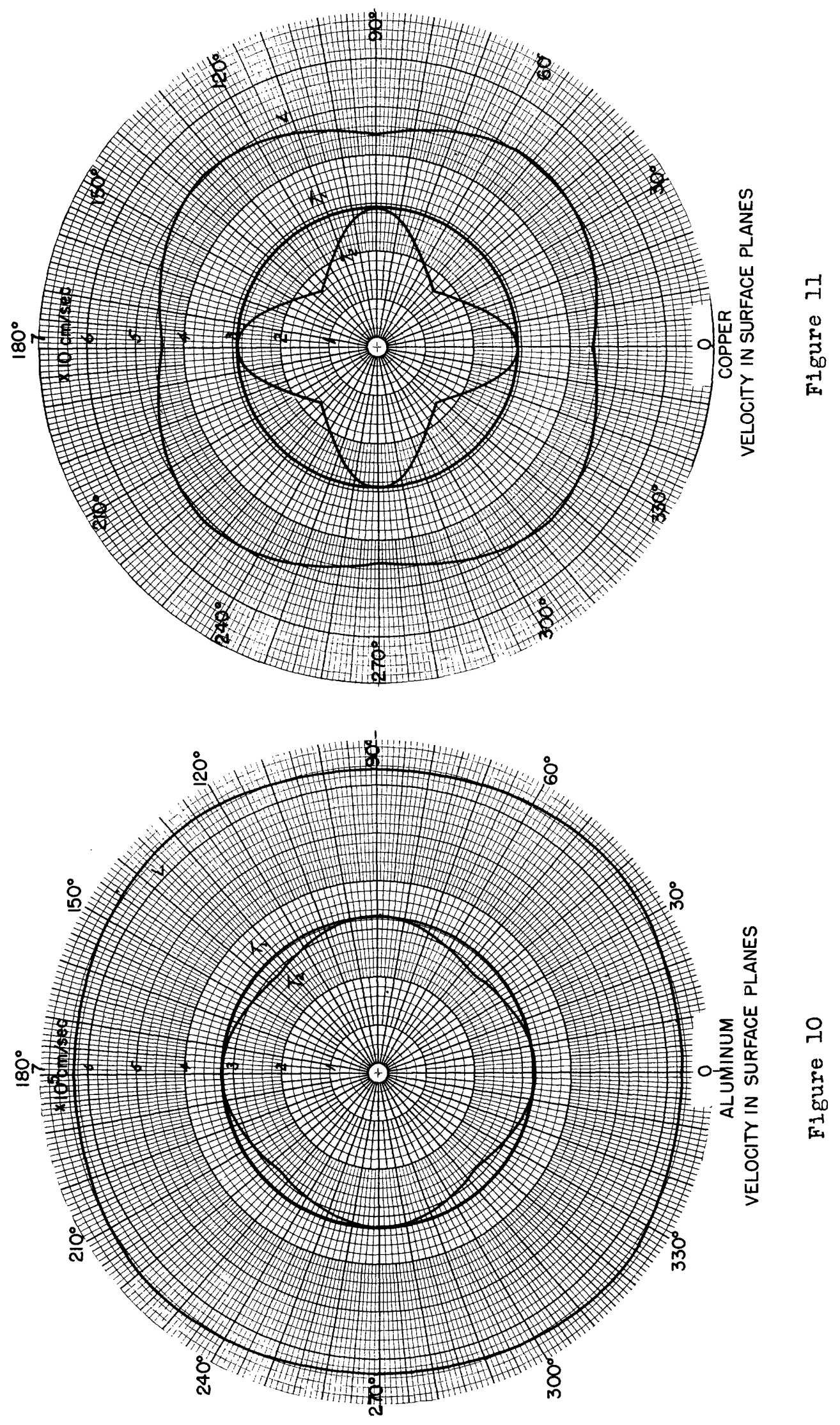

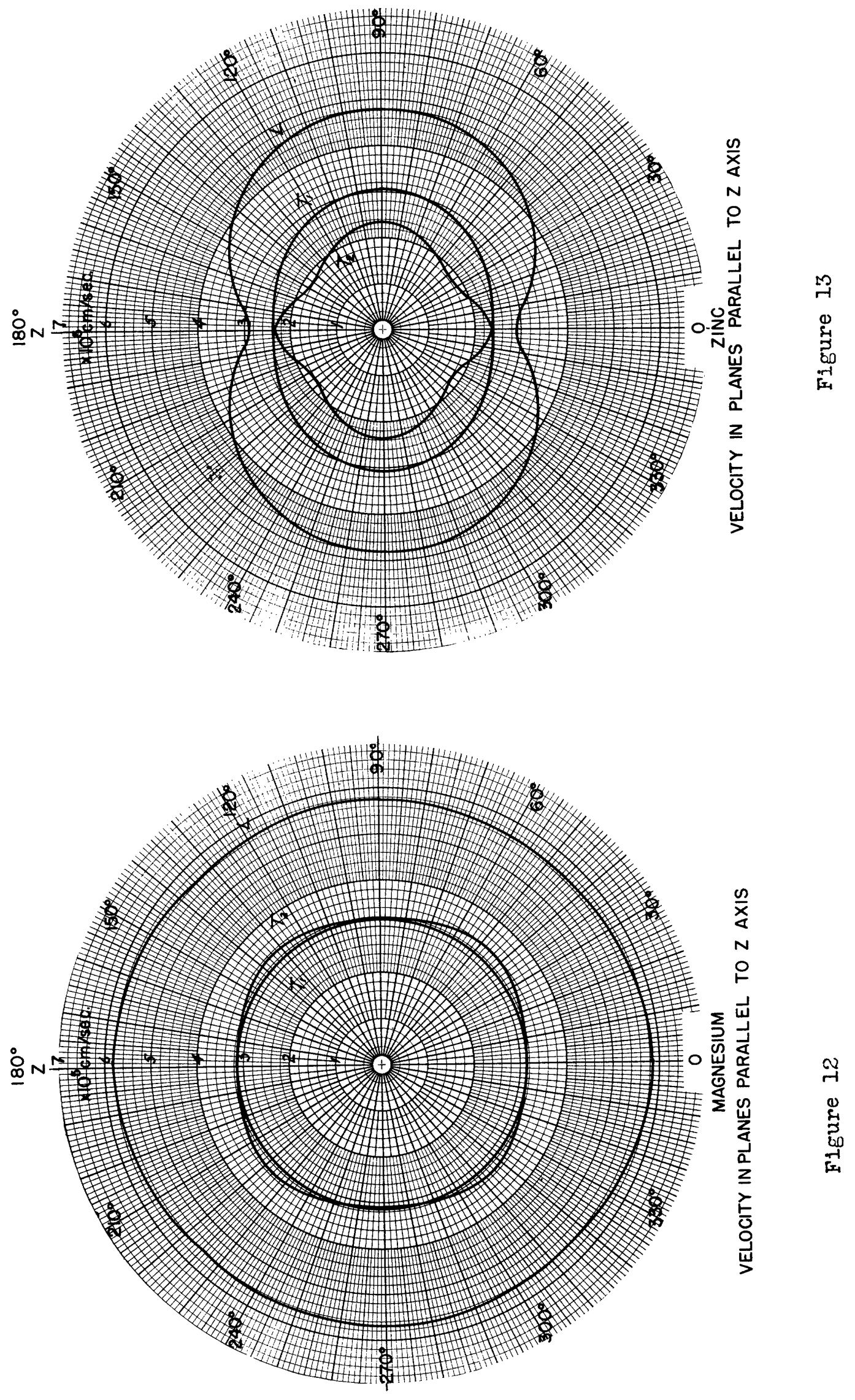
to the incldent pulse at the grain boundaries. The greater the anisotropy of the grain, the greater the scattering. A metal composed of isotropic grains, which have circular velocity polar plots, would not produce scattering since no discontinulties would be introduced by grain boundaries. This concept enables us to establish a basis of comparison or figures of merit for judging the fidelity of pulse transmission for any metal. The strains in a solid can be expressed in terms of the stress if the elastic moduli matrix for the solid is known. The only difference between the cubic matrix and the isotropic matrix is that in the former case $s_{44} / 2\left(s_{1 I}-s_{12}\right] \neq I$ where $s_{1 k}$ are the elements of the matrices. The hexagonal matrix has the additional inequalities, $s_{13} / s_{12} \neq I$ and $s_{33} / s_{1 I} \neq 1$. If the substance were 1sotropic, these respective inequalities would not exist; hence this departure can be used as a figure of merit. Table III lists all cublc and hexagonal metals whose constants are given by Hearmon, and the departure of the listed values from unity is a measure of the anisotropy. The experimental observations in several of the cases agree with these predictions as noted below. Tungsten is the only outstanding example of an isotropic solid included here. It should transmit pulses with little scattering and, hence, with good fidelity even at high ultrasonic frequencies.

Acknowledgements. The author wishes to thank Professor Julius A. Stratton for his continuous interest in this research program and Professor Morris Cohen for his cooperation throughout the metallurgical phases of the woris. It is with especial pleasure that he acknowledges the assistance of Professor Hans Mueller, under whose guldance this research was conducted.

I. R. F. S. Hearmon, "Elastic Constants of Anistropic Materials". Rev. Mod. Phys. 18, (3) July 1946, p. 409. 
TABLE III. Risures of Merit for Pulse Transmisston

Cubic Srstem Allorg

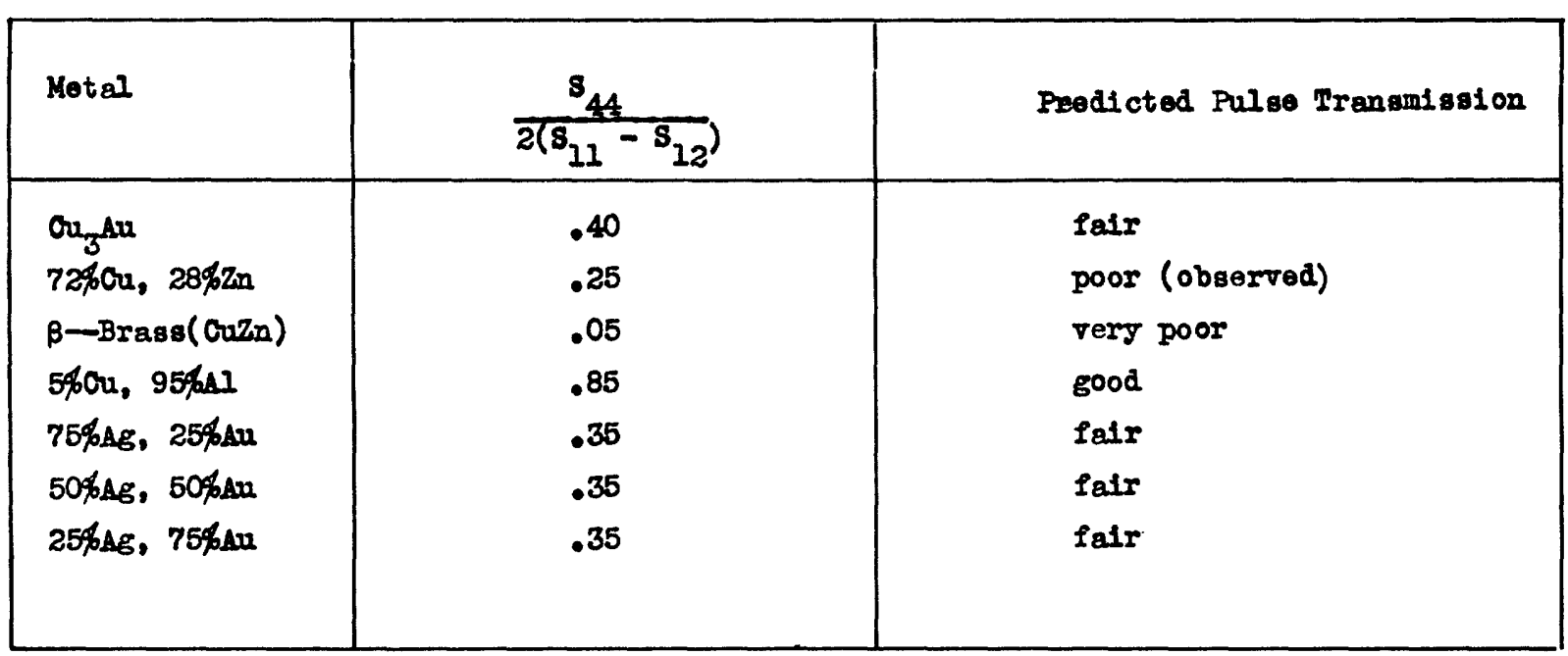

Cubic System Iloments

\begin{tabular}{|l|l|l|}
\hline Metal & $\frac{\mathrm{s}_{44}}{2\left(\mathrm{~s}_{11}-\mathrm{s}_{12}\right)}$ & Predicted Pulse Transmission \\
\hline ul & .81 & good (observed) \\
Ou & .31 & poor (observed) \\
Au & .35 & fair \\
Po & .42 & fair \\
Pb & .26 & poor \\
K & .16 & poor \\
Ag & .35 & fair \\
Na & .14 & poor \\
W & 1.0 & excellent \\
\hline
\end{tabular}

Hexagonal System Hlements (5 coefficients)

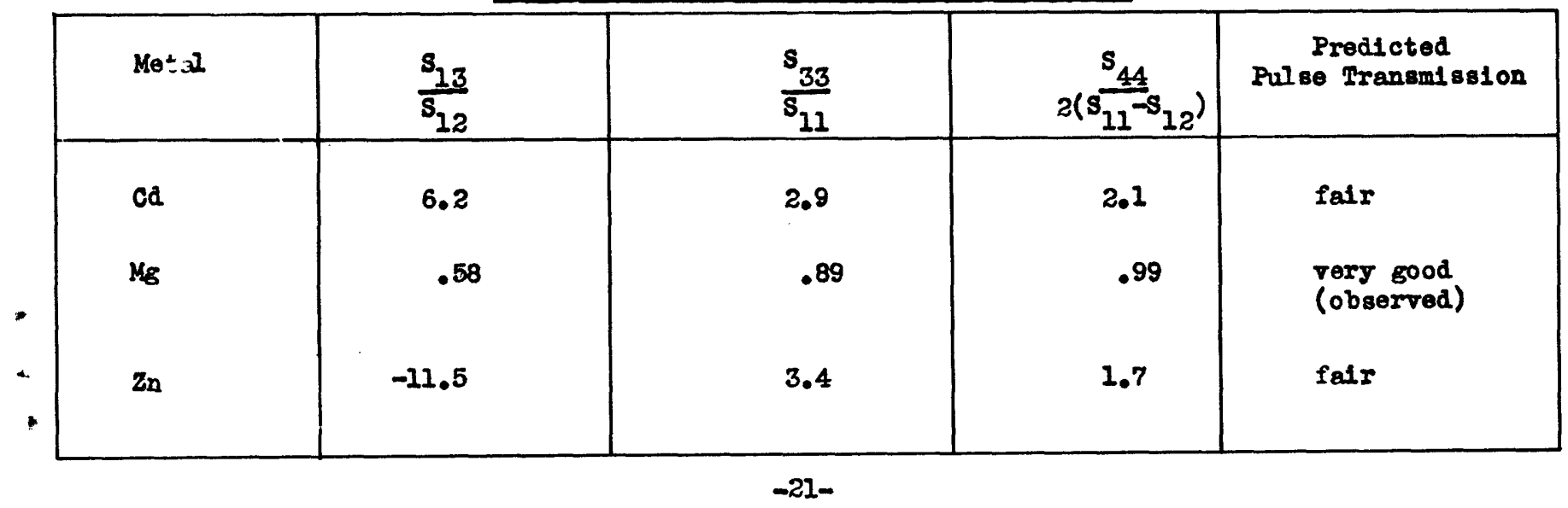


